\title{
METABOLISM OF FATTY ACIDS AND THE LEVELS OF KETONE BODIES IN THE LIVERS OF PYRIDOXINE-DEFICIENT RATS
}

\author{
Shuzo Gomikawa and Mitsuko OKADA ${ }^{1}$ \\ Department of Nutrition, School of Medicine, Tokushima University, \\ Tokushima 770, Japan \\ (Received June 30, 1977)
}

\begin{abstract}
Summary Lipid metabolism was examined in rats fed a high-protein pyridoxine-deficient diet, and their livers were found to contain large amounts of lipids, mainly in the forms of triglycerides and cholesteryl ester. The contents of ketone bodies in the livers of pyridoxine-deficient and the control rats were similar. Their $\mathrm{NAD}^{+} / \mathrm{NADH}$ ratios, calculated from the amounts of ketone bodies, were also similar in pyridoxinedeficient and control groups when the animals were fed, but the ratio in pyridoxine-deficient rats was lower than that of control rats when the animals were starved. After injection of ${ }^{14} \mathrm{C}$-linoleic acid, the amounts of expired ${ }^{14} \mathrm{CO}_{2}$ in pyridoxine-deficient and control rats were similar. The pattern of incorporations of ${ }^{14} \mathrm{C}$-linoleic acid into various lipid components of the livers were examined; incorporation into the phospholipid fraction was similar in control and deficient rats, but the incorporation into the triglyceride fraction was slower, and the incorporation into cholesterol was faster in deficient animals than in controls.
\end{abstract}

Vitamin $B_{6}$ is known to be involved in lipid metabolism. Swell et al. (1), and SCHEIER and Williams (2) reported that vitamin $B_{6}$ is related to the conversion of linoleic acid to arachidonic acid, but other investigators $(3,4)$ failed to confirm this role of vitamin $\mathrm{B}_{6}$. DUSSAULT and LEPAGE (5) suggested that vitamin $\mathrm{B}_{6}$ might be connected with catabolism of arachidonic acid. The lipid content of the livers has been reported to be lowered $(1,6,7)$ or unchanged in pyridoxine deficiency $(8)$. Recently we found that the dietary protein level influenced lipid metabolism in pyridoxine-deficient rats $(9,10)$. On feeding a high $(70 \%)$ protein diet, deficient rats accumulated triglyceride and cholesteryl ester in the liver. Both LUPIEN et al. (11-13) and SHAH et al. (14) observed no change in the cholesterol content but observed an increase in cholesterogenesis in the livers in pyridoxine-deficient rats. We also obtained evidence for increased cholesterogenesis

1 五味川修三，岡田美津子 
from acetate in rats fed a $70 \%$-casein pyridoxine-deficient diet (15). We are interested in the mechanism of fatty liver induced by a high-protein pyridoxinedeficiency. It is known that this fatty liver is not caused by a decreased synthesis of lipoprotein (16) or choline deficiency (10). In the present work we studied the incorporation of linoleic acid into various lipid components and fatty acid oxidation in pyridoxine-deficient rats in vivo. We also determined ketone bodies in their livers in relation to cholesterol metabolism.

\section{MATERIALS AND METHODS}

Male Wistar strain rats were purchased from Nishin Kikai Co. All dietary materials except vitamin-free casein (NBC) were obtained from Tanabe Amino Acid Research Foundation, and 3-hydroxybutyrate dehydrogenase [EC 1.1.1.30], NAD and NADH were from Boehringer Mannheim. $1-{ }^{14} \mathrm{C}$-Linoleic acid (35 $\mathrm{mCi} / \mathrm{mmole}$ ) was from Daiichi Pure Chemicals Co., Ltd.

Animals. Rats were maintained on a $20 \%$ casein diet for 3 days. Then rats weighing 50 to $60 \mathrm{~g}$ were fed a $70 \%$ casein diet for 3 to 4 weeks. The composition of the diet (in $\mathrm{g}$ ) was the same as described previously (17): vitamin-free casein, 70; sucrose, 10; cornstarch, 7; oil mixture, 8; choline chloride, 0.2 ; salt mixture, 4; vitamin mixture with or without pyridoxine, 1 . The rats were divided into two groups: the pyridoxine-deficient animals received the diet ad libitum and the control animals were pair-fed with the deficient animals on a pyridoxinesupplemented diet. Radioactive potassium linoleate was prepared by adding alcoholic $\mathrm{KOH}$ to dried ${ }^{14} \mathrm{C}$-linoleic acid, and emulsified by adding $0.9 \% \mathrm{NaCl}$ and defatted bovine serum albumin (18). This emulsion contained $50 \mu \mathrm{Ci} / \mathrm{ml}$ $(1.42 \mu$ mole $)$ and doses of $0.1 \mathrm{ml}$ per $100 \mathrm{~g}$ body weight were injected into the tail vein of rats (19). Rats were usually sacrificed between 10:00 and 12:00 hr to determine incorporation of ${ }^{14} \mathrm{C}$-linoleic acid into their lipid fractions.

Preparation of liver powder. Animals were decapitated and their livers were rapidly removed and immersed in dry ice-acetone. The frozen liver was pulverized to fine powder in a Waring blender and samples of the powder were used to determine ketone bodies and lipids.

Determination of ketone bodies. Liver samples were prepared by the method of BERRY et al. (20): the frozen liver powder was homogenized in $30 \% \mathrm{HClO}_{4}$ and the supernatant was neutralized with $\mathrm{KOH}$; the mixture was centrifuged and samples of the supernatant were treated with florisil to remove flavin and analysed for $\beta$-hydroxybutyrate and acetoacetate enzymatically (21). $\mathrm{NAD}^{+} / \mathrm{NADH}$ ratios were calculated from the concentrations of these ketone bodies by the method of WiLliamson et al. (22).

Extraction and assay of liver lipids. Samples of liver were homogenized in $0.9 \% \mathrm{NaCl}$ solution, and the lipids were extracted by the method of FolCH et al. (23), and determined gravimetrically as described before (17). The lipid fraction was separated by thin-layer chromatography on a silica gel $G$ plate with a 
mixture of petroleum ether-ethyl ether-acetic acid (80:20:1, by vol.) as solvent. The bands of lipid on the plate were detected with iodine vapor and scrapped off. Free cholesterol, cholesteryl ester and triglyceride were extracted with chloroform-methanol ( $2: 1$, by vol.), and cholesterol (free and ester) and triglyceride were measured by the method of ZAK (24) and a modification of the method of VAN HANDEL (25), respectively. Phospholipid was either measured directly in the crude lipid fraction as inorganic phosphate by a slightly modification of the method of HoELMAYER-FrIED (26), or it was extracted from the thin-layer chromatogram with chloroform-methanol-acetic acid-water (50:39:1:10, by vol.) (27). The recoveries of cholesterol, cholesteryl ester and triglyceride were over $95 \%$, and that of phospholipid was about $70 \%$. The cholesteryl ester fraction was hydrolyzed by a modification of the method of FLINT (28); then the hydrolysate was rechromatographed, and the fractions corresponding to cholesterol and cholesteryl ester were eluted and their radioactivities were determined. The radioactivities of the fatty acid and cholesterol moiety were calculated as follows:

$$
C_{(\mathrm{e})}=C E \times \frac{C}{C+F}, \quad F_{(\mathrm{e})}=C E \times \frac{F}{C+F} .
$$

Where $C_{(\mathrm{e})}$ is the activity of the cholesteryl moiety, $F_{(e)}$ is that of esterified fatty acid, $C E$ is that of cholesteryl ester before hydrolysis, $C$ is that of cholesterol after hydrolysis and $F=C E-(C+$ radioactivity of cholesteryl ester remained after hydrolysis). The rates of hydrolysis were more than $90 \%$ under the conditions used. Determination of expired ${ }^{14} \mathrm{CO}_{2}$. The expired ${ }^{14} \mathrm{CO}_{2}$ from a rat injected with ${ }^{14} \mathrm{C}$-linoleic acid was collected for 1 hour in ethanolamine-ethyleneglycol monomethylether $(1: 2$, by vol.) by application of a negative pressure of $7-8 \mathrm{mmHg}(29$, 30 ) and the radioactivity was determined.

Measurement of radioactivities. The radioactivities of lipid fractions and $\mathrm{CO}_{2}$ were measured in toluene-based scintillator and toluene-ethyleneglycol monomethylether (2: 1 , by vol.) scintillator, respectively, with an Aloka liquid scintillation counter.

\section{RESULTS}

\section{Contents of liver lipids}

As described before $(9,10)$, the amounts of lipids, and especially triglyceride and cholesteryl ester in the liver were higher in pyridoxine-deficient rats than in the controls (Table 1).

\section{Levels of ketone bodies and the $N A D^{+} / N A D H$ ratio}

The accumulation of cholesteryl ester in the liver of pyridoxine-deficient rats prompted us to test whether the synthesis of ketone bodies decreased in the deficient rats. Accordingly, we measured the amounts of $\beta$-hydroxybutyrate and acetoacetate in the livers of fed and starved (for 14 hours) rats. As shown in 
Table 1. Analysis of liver lipid.

\begin{tabular}{cccccc}
\hline Diet & $\begin{array}{c}\text { Total lipid } \\
(\mathrm{mg} / \mathrm{g})\end{array}$ & $\begin{array}{c}\text { Phospholipid Triglyceride } \\
(\mu \mathrm{mole} / \mathrm{g})\end{array}$ & $\begin{array}{c}\text { Free } \\
(\mu \mathrm{mole} / \mathrm{g})\end{array}$ & $\begin{array}{c}\text { Cholesteryl } \\
(\mu \mathrm{mole} / \mathrm{g})\end{array}$ & $\begin{array}{c}\text { ester } \\
(\mu \mathrm{mole} / \mathrm{g})\end{array}$ \\
\hline Deficient (10) & $71.3 \pm 21.1$ & $47.2 \pm 8.76$ & $21.4 \pm 14.8$ & $4.53 \pm 0.70$ & $1.77 \pm 0.94$ \\
Control (10) & $43.4 \pm 2.53$ & $46.6 \pm 10.4$ & $3.72 \pm 0.88$ & $4.34 \pm 0.33$ & $0.76 \pm 0.17$ \\
\hline$p$ & $<0.001$ & $\mathrm{~ns}$ & $<0.001$ & $\mathrm{~ns}$ & $<0.001$ \\
\hline
\end{tabular}

ns: not significant as compared to control. Feeding conditions are described in the text. Figures in parentheses are number of rats. Values are expressed as means \pm S.D.

Table 2, when the rats were fed, the amounts of both $\beta$-hydroxybutyrate and acetoacetate were similar in the pyridoxine-deficient and control groups. In starved rats, the level of $\beta$-hydroxybutyrate in the liver of pyridoxine-deficient rats tended to increase, but this increase was not significant $(p>0.05)$. Thus the levels of total ketone bodies were similar in pyridoxine-deficient and control animals. Redox state in various compartment can be calculated by measuring the ratio of the concentrations of the oxidized and reduced metabolites of suitable NAD-linked dehydrogenase systems that are located in different cell compartments. WiLliamson et al. (22) showed that the use of $\beta$-hydroxybutyrate-acetoacetate system is suitable for the assessment of the $\mathrm{NAD}^{+} / \mathrm{NADH}$ ratio within the rat liver mitochondria. The $\mathrm{NAD}^{+} / \mathrm{NADH}$ ratios were therefore calculated from the these levels of ketone bodies (Table 3); when the rats were fed, the $\mathrm{NAD}^{+} / \mathrm{NADH}$ ratios of pyridoxine deficient and control rats were similar, whereas when the rats were starved, the ratio was lower in the deficient rats due to increase in NADH.

\section{Metabolism of linoleic acid in vivo}

After injection of ${ }^{14} \mathrm{C}$-linoleic acid, the expired ${ }^{14} \mathrm{CO}_{2}$ was collected for 1 hour and its radioactivity was determined. As shown in Table 4, there was no difference in the radioactivities in two groups. The incorporations of injected ${ }^{14} \mathrm{C}$ linoleic acid into various lipid fractions were also determined after various times; linoleic acid was incorporated into the phospholipid fraction of pyridoxine-deficient rats rather slowly but very similar pattern were observed in the two groups (Fig. 1). The incorporation of linoleic acid into triglycerides is shown in Fig. 2; slow incorporation and delayed removal of triglycerides were observed in the deficient group. Figure 3 shows the incorporation of linoleic acid into the free cholesterol fraction; the rate of incorporation was greatly increased in the deficient animals, but the rates of removal of radioactivity from the cholesterol fraction were similar in the two groups. The incorporations of linoleic acid into cholesteryl ester were initially similar in the two groups, but later the pyridoxine-deficient rats showed increased incorporation (Fig. 4). The radioactivities incorporated in the earlier period were found entirely in the fatty acid moiety of cholesteryl ester in both groups (Table 5). 


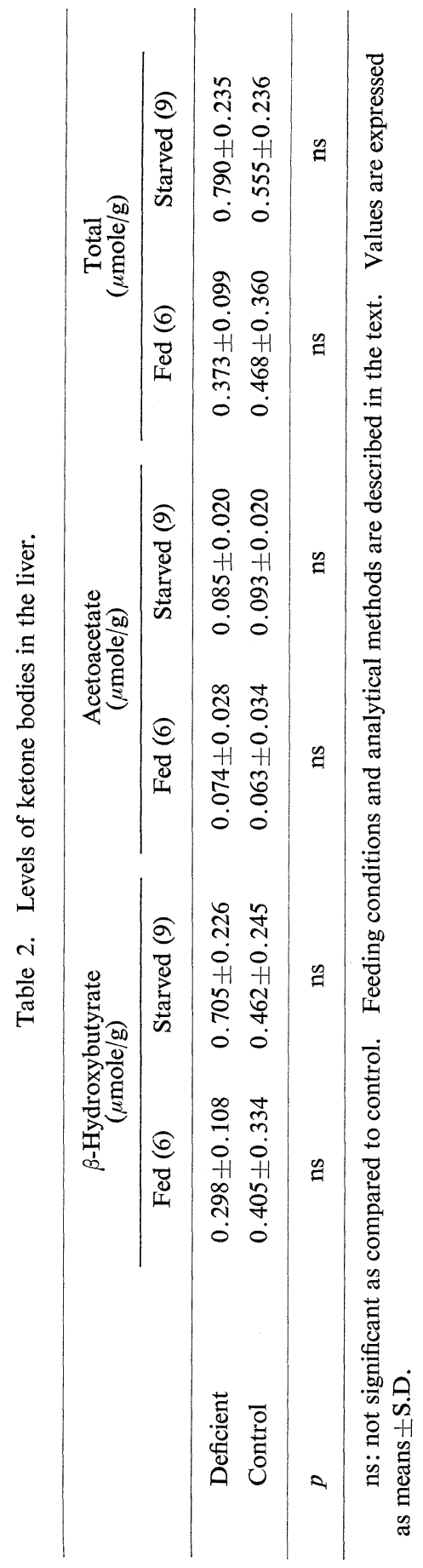




\section{DISCUSSION}

Pyridoxine deficiency is known to disturb lipid metabolism. We previously reported increases in the contents of triglyceride and cholesteryl ester in the liver of rats fed a high-protein pyridoxine-deficient diet $(9,31)$, and we confirmed these results in the present study (Table 1). Cholesterol and ketone bodies are

Table 3. Redox state of liver mitochondria.

\begin{tabular}{lccccc}
\hline & \multicolumn{2}{c}{$\beta$-Hydroxybutyrate/Acetoacetate } & & \multicolumn{2}{c}{ NAD $^{+} / \mathrm{NADH}^{2}$} \\
\cline { 2 - 3 } \cline { 5 - 6 } & Fed (6) & Starved (9) & & Fed (6) & Starved (9) \\
\hline Deficient & $4.86 \pm 3.28$ & $8.36 \pm 2.41$ & & $6.06 \pm 3.37$ & $2.60 \pm 0.64$ \\
Control & $4.88 \pm 2.85$ & $4.30 \pm 2.02$ & & $5.42 \pm 3.01$ & $5.99 \pm 3.21$ \\
\hline$p$ & $\mathrm{~ns}$ & $<0.01$ & & ns & $<0.01$ \\
\hline
\end{tabular}

ns: not significant as compared to control.

$\mathrm{NAD}^{+} / \mathrm{NADH}$ was calculated from $\frac{\text { [Acetoacetate] [NADH] }}{\left[\beta \text {-Hydroxybutyrate] }\left[\mathrm{NAD}^{+}\right]\right.}=K, \quad K=4.93 \times 10^{-2} \mathrm{~mm}$ obtained by Williamson et al. (22), was used in this calculation $\left(38^{\circ} \mathrm{C}, \mathrm{pH} 7.0\right.$ and $\left.\mathrm{I}, 0.25\right)$.

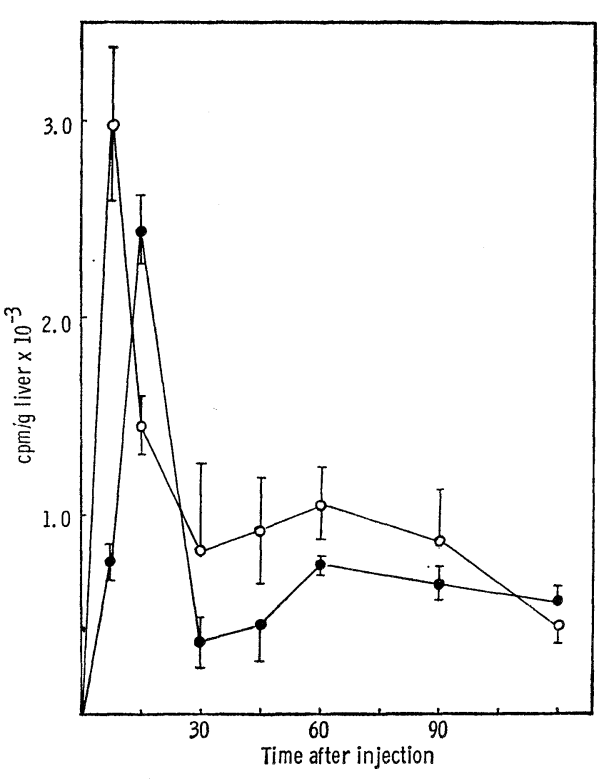

Fig. 1.

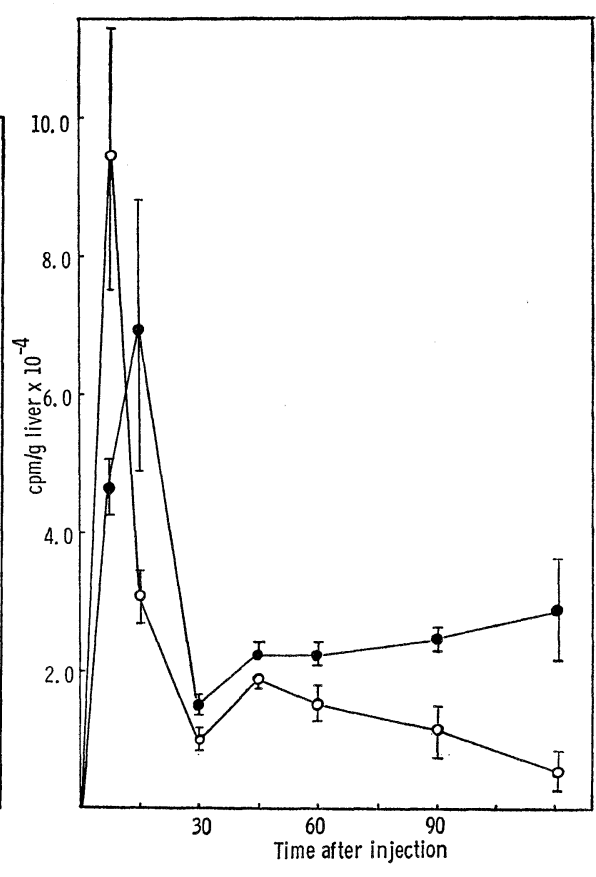

Fig. 2.

Fig. 1. Incorporation of ${ }^{14} \mathrm{C}$-linoleic acid into phospholipid. $\quad$, Deficient; $\bigcirc$, control. The same animals were used in the experiments shown in Fig. 1-4. Experimental conditions were described in the text. Vertical lines show the extents of standard deviations.

Fig. 2. Incorporation of ${ }^{14} \mathrm{C}$-linoleic acid into triglyceride. $\bullet$, Deficient; $\bigcirc$, control. 
both synthesized via 3-hydroxy-3-methylglutaryl CoA $(32,33)$. Thus the accumulation of cholesteryl ester in the pyridoxine-deficient rats suggested that the syntheses of ketone bodies might be abnormal. But does not seen to be so,

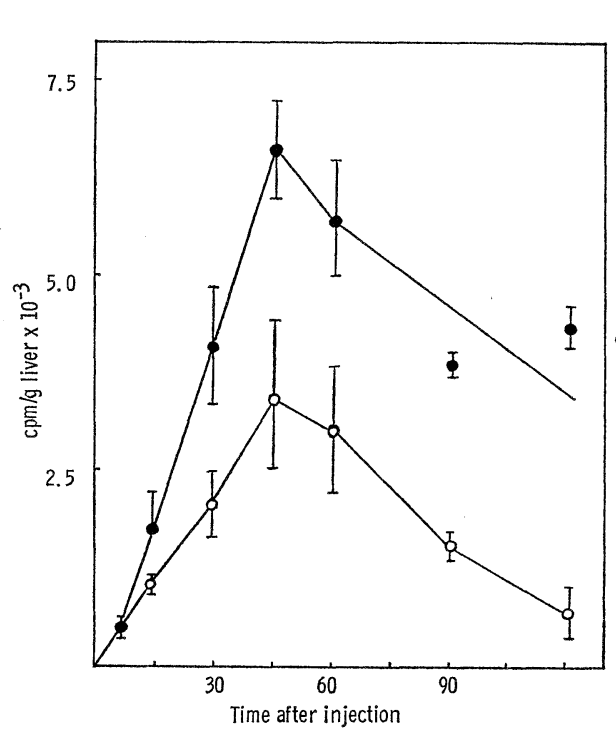

Fig. 3.

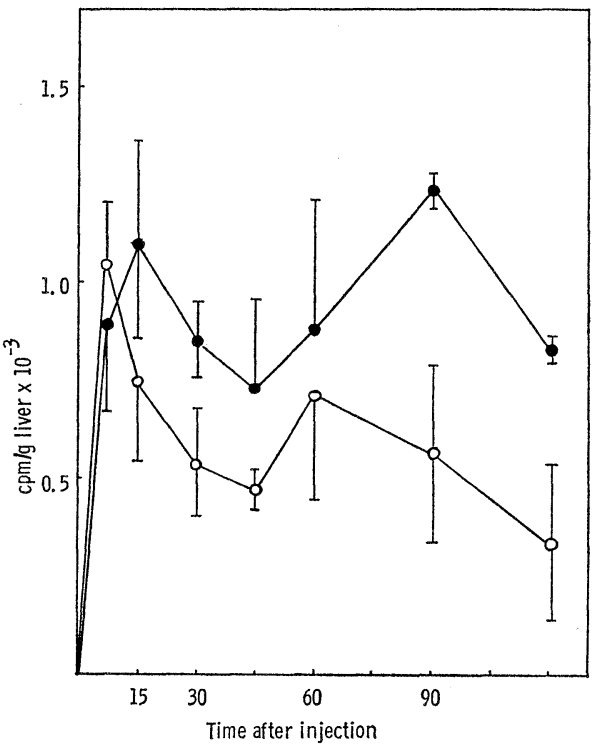

Fig. 4.

Fig. 3. Incorporation of ${ }^{14} \mathrm{C}$-linoleic acid into cholesterol. $\quad$, Deficient; $O$, control.

Fig. 4. Incorporation of ${ }^{14} \mathrm{C}$-linoleic acid into cholesteryl ester. ๑, Deficient; $O$, control.

Table 4. Liberation of ${ }^{14} \mathrm{CO}_{2}$ from ${ }^{14} \mathrm{C}$-linoleic acid.

\begin{tabular}{lc}
\hline & $\mathrm{cpm} / 100 \mathrm{~g}$ body weight $\times 10^{-4}$ \\
\hline Deficient (4) & $102.00 \pm 6.55$ \\
Control (4) & $135.00 \pm 35.60$ \\
\hline$p$ & ns
\end{tabular}

ns: not significant as compared to control. Experimental conditions are described in the text. Values are expressed as means \pm S.D.

Table 5. Distribution of radioactivities in cholesteryl ester.

\begin{tabular}{lrccl}
\hline & min* & Deficient (4) & Control (4) & $p$ \\
\hline Fatty acids & 7.5 & $650 \pm 291$ & $947 \pm 173$ & ns \\
(cpm/g) & 15.0 & $975 \pm 251$ & $767 \pm 134$ & ns \\
\hline Cholesterol & 7.5 & $81 \pm 54$ & $79 \pm 1$ & ns \\
(cpm/g) & 15.0 & $81 \pm 50$ & $54 \pm 13$ & ns \\
\hline
\end{tabular}

* Time after injection. ns: not significant as compared to control. This experiment was carried out using the same animals as in Fig. 1-4. Experimental conditions were described in the text. Values are expressed as means \pm S.D. 
because we could not detect any appreciable difference the levels of ketone bodies in the livers of pyridoxine-deficient and control animals. Recently, ClinkenBEARD et al. (34) suggested that there might be separate pools of 3-hydroxy-3methylglutaryl CoA. Fatty liver may also be caused by impaired oxidation of fatty acid: ARTOM (35) reported inhibition of oxidation of stearic acid in animals treated with DL-ethionine and CORREDOR (36) also described impaired oxidation of long chain fatty acid in choline-deficient animals. However, in this work we obtained no evidence for impaired oxidation of fatty acids in pyridoxine-deficient rats from either the mitochondrial $\mathrm{NAD}^{+} / \mathrm{NADH}$ ratio, calculated from the values for ketone bodies, or results on the oxidation of injected ${ }^{14} \mathrm{C}$-linoleic acid (Tables 3 and 4). We also observed no difference in the oxidations of acetate in liver slices from pyridoxine-deficient and control rats (31). Studies on the pool sizes of fatty acids in pyridoxine-deficient and control animals are necessary to clarify this problem.

In this work we also examined the incorporation of ${ }^{14} \mathrm{C}$-linoleic acid into phospholipids. The radioactivities in phospholipids may be largely due to that in phosphatidic acid, which has a more rapid turnover than other phospholipids $(27,37)$. The incorporation of ${ }^{14} \mathrm{C}$-linoleic acid into triglycerides in pyridoxinedeficient and control rats were different from 45 minutes after the times of injection (Fig. 2); the slower removal of radioactivity in deficient rats may be due to impaired oxidation, impaired secretion from the liver or increased influx from extrahepatic tissues. It could also be due to indirect utilization of linoleic acid from fatty ester other than triglyceride (38) or reutilization of acetate produced from linoleic acid. In the latter case the glycerol moiety of triglycerides may also contain radioactivity. Increased cholesterogenesis in the livers of rats fed a pyridoxine-deficient diet has been reported from this laboratory and by others $(11-15,31)$, and it was confirmed in the present study using ${ }^{14} \mathrm{C}$-linoleic acid (Fig. 3). As shown in Fig. 4, the rates of esterification of cholesterol in the deficient and control groups were very similar. Thus it seems likely that cholesteryl ester accumulates in the liver of pyridoxine-deficient rats because synthesis of the cholesterol moiety increases, rather than because the rate of esterification increases.

\section{REFERENCES}

1) Swell, L., Law, M. D., Schools, P. E., Jr., and Treadwell, C. R. (1961): Tissue lipid fatty acid composition in pyridoxine-deficient rats. J. Nutr., 74, 148-156.

2) Scheier, G. E., and Williams, M. A. (1964): Sequential changes in liver and heart lipids after giving linoleate or linoleate plus pyridoxine to rats depleted of fat and pyridoxine. Biochem. J., 92, 422-429.

3) Kurschman, J. C., and Coniglio, J. G. (1961): The role of pyridoxine in the metabolism of polyunsaturated fatty acids in rats. J. Biol. Chem., 236, 2200-2203.

4) SöDERHJELM, L. (1962): Influence of pyridoxine and dietary fat on the distribution of serum fatty acids in dogs. J. Nutr., 78, 438-444.

5) Dussault, P. E., and Lepage, M. (1975): Effects of pyridoxine deficiency on the com- 
position of plasma and liver fatty acids in rats fed low and high fat diets. J. Nutr., 105, 1371-1376.

6) Carter, C. W., and Phizackerley, J. R. (1951): The influence of pyridoxine on fat metabolism in the rat. Biochem. J., 49, 227-232.

7) Audet, A., and Lupien, P. J. (1974): Triglyceride metabolism in pyridoxine-deficient rats. J. Nutr., 104, 91-100.

8) Desikachar, H. S. R., and McHenry, E. W. (1954): Some effects of vitamin $B_{6}$ deficiency on fat metabolism in rats. Biochem. J., 56, 544-547.

9) OKADA, M., and OCHI, A. (1971): Effect of dietary composition on vitamin $\mathrm{B}_{6}$ deficiency state (II). Fatty liver induced by high protein diet without $\mathrm{B}_{6}$. Vitamins (in Japanese), 43, 241-244.

10) Suzuki, K., Nakamura, T., Fujita, M., Iwami, T., Abe, M., and Okada, M. (1976): Factors affecting liver lipid content in pyridoxine-deficient rats. I. Dietary protein levels. J. Nutr. Sci. Vitaminol., 22, 291-298.

11) Lupien, P. J., Hinse, C. M., and Avery, M. (1969): Cholesterol metabolism and vitamin $\mathbf{B}_{6}$. I. Hepatic cholesterogenesis and pyridoxine deficiency. Can. J. Biochem., 47, 631-635.

12) Hinse, C. M., and LupIEN, P. J. (1971): Cholesterol metabolism and vitamin $B_{6}$. III. The stimulation of hepatic cholesterogenesis in the vitamin $\mathrm{B}_{6}$-deficient rat. Can. J. Biochem., 49, 933-935.

13) Avery, M. D., and Lupien, P. J. (1971): Cholesterol metabolism and vitamin B $_{6}$. IV. Synthesis of cholic acid conjugates in vitamin $\mathrm{B}_{6}$-deficient rats. Can. J. Biochem., 49, 1026-1030.

14) Shah, S. N., Johnston, P. V., and Kummerow, F. A. (1960): The effect of pyridoxine on cholesterol metabolism. J. Nutr., 72, 81-86.

15) Suzuki, K., and Okada, M. (1973): Seikagaku (in Japanese, Abstract of Japanese Biochemical Society), 45, 529.

16) Okada, M., and Suzuki, K. (1974): Amino acid metabolism in rats fed a high protein diet without pyridoxine. J. Nutr., 104, 287-293.

17) OKadA, M., and OcHI, A. (1971): The effect of dietary protein level on transaminase activities and fat deposition in vitamin $\mathrm{B}_{6}$-depleted rat liver. J. Biochem., 70, 581-585.

18) Garland, P. B., Newsholme, E. A., and Randle, P. J. (1964): Regulation of glucose uptake by muscle. Biochem. J., 93, 665-678.

19) Schotz, M. C., and Olivercrone, T. (1966): The effect of anesthesia on the fate of injected free fatty acid. Biochim. Biophys. Acta, 125, 174-175.

20) Berry, M. N., Williamson, D. H., and Wilson, M. B. (1965): Concentrations of acetoacetate and $\mathrm{D}(-)-3$-hydroxybutyrate in rat liver and blood. Biochem. J., 94, 17c-19c.

21) Williamson, D. H., Mellanby, J., and Krebs, H. A. (1962): Enzymic determination of $D(-)$ - $\beta$-hydroxybutyric acid and acetoacetic acid in blood. Biochem. J., 82, 90-96.

22) Williamson, D. H., Lund, P., and Krebs, H. A. (1967): The redox state of free nicotinamide-adenine dinucleotide in the cytoplasm and mitochondria of rat liver. Biochem. J., 103, 514-527.

23) Folch, J., Lees, M., and Sloane-Stanley, G. H. (1957): A simple method for the isolation and purification of total lipids from animal tissues. J. Biol. Chem., 226, 497-509.

24) ZAK, B. (1957): Simple rapid microtechnique for serum total cholesterol. J. Clin. Path., 27, 583-588.

25) Kawade, M. (1966): Rinsho-kagaku Bunseki, Tokyo Kagaku Dojin, Vol. 3, p. 40.

26) KuJyo, H., and FukuI, I. (1967): Determination of serum phospholipids. The method of Hoelfmayr-Fried. Rinsho Byori, 15, 853-856.

27) Åkesson, B. (1970): Initial esterification and conversion of intraportally injected $\left[1-{ }^{14} \mathrm{C}\right]-$ 
linoleic acid in rat liver. Biochim. Biophys. Acta, 218, 57-70.

28) Flint, A. P. F., and Denton, R. M. (1969): Glucose metabolism in the superovulated rat ovary in vitro. Effects of luteinizing hormone and the role of glucose metabolism in steroidogenesis. Biochem. J., 112, 243-254.

29) Arthur, F. A., and von Schuching, S. L. (1970): Catabolism of ascorbic acid labeled with radioactive carbon to $\mathrm{CO}_{2}$. Excretory pathway of ${ }^{14} \mathrm{CO}_{2}$ by respiratory exhalation, in Methods in Enzymology, ed. by Colowick, S. P. and Kaplan, N. O., Academic Press, New York and London, Vol. 18, pp. 34-46.

30) Jeffay, H., and Alvarez, J. (1961): Liquid scintillation counting of carbon-14 use of ethanolamine-ethylene glycol monomethyl ether-toluene. Anal. Chem., 33, 612-615.

31) Iwami, T., Suzuki, K., and OKada, M. (1975): Seikagaku (in Japanese, Abstract of Japanese Biochemical Society), 47, 501.

32) Barth, C. A., Hackenschmidt, H. J., Weis, E. E., and Decher, K. F. A. (1973): Influence of kynurenate on cholesterol and fatty acid synthesis in isolated perfused rat liver. $J$. Biochem., 248, 738-739.

33) Williamson, D. H., Bates, M. W., and Krebs, H. A. (1968): Activity and intracellular distribution of enzymes of ketone-body metabolism in rat liver. Biochem. J., 108, 353-361.

34) Clinkenbeard, K. D., Reed, W. D., Mooney, R. A., and Lane, M. D. (1975): Intracellular localization of the 3-hydroxy-3-methylglutaryl coenzyme A cycle enzymes in liver. $J$. Biol. Chem., 250, 3108-3116.

35) АRтом, C. (1959): Fatty acid oxidation in the livers of rats receiving DL-ethionine. $J$. Biol. Chem., 234, 2259-2264.

36) Corredor, C., Mansbach, C., and Bressler, R. (1967): Carnitine depletion in the choline-deficient state. Biochim. Biophys. Acta, 144, 366-374.

37) VAVReČKa, M., Mitchell, M. P., and HüBsCher, G. (1969): The effect of starvation on the incorporation of palmitate into glycerides and phospholipids of rat liver homogenates. Biochem. J., 115, 139-145.

38) BAKER, N., and SchotZ, M. C. (1967): Quantitative aspects of free fatty acid metabolism in the fasted rat. J. Lipid Res., 8, 646-660. 